\title{
Health Canada to warn young people of cannabis risks in campaign
}

\author{
n Cite as: CMAJ 2017 October 16;189:E1297. doi: 10.1503/cmaj.109-5506
}

Posted on cmajnews.com on September 25, 2017.

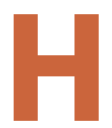
ealth Canada has issued a public tender to find a contractor to develop a national marketing plan targeting youth that will focus on "education and awareness of health and safety risks of cannabis." The campaign will target Canadian youth (age 13-18) and young adults (18-24). It will run after December 2017 until March 2019, and may change in focus if the proposed legislation to legalize marijuana (Bill C-45, The Cannabis Act) becomes law.

"Canadians need to be educated about the use of cannabis in order to mitigate its potential risks and harms," stated the tender. "They generally view cannabis use as socially acceptable, but are illinformed about the health and safety risks; this is especially true for youth."

Among the key messages will be that using cannabis, like alcohol, is not without health risks - and the risks are higher for people who start using the drug at a younger age. The campaign will also encourage young people to choose "positive and healthy lifestyles, including avoiding cannabis" so they can reach their full potential.

Health Canada plans to hold different types of events for the two age ranges they want to target. For Canadians age 13-18, at least five events are suggested, which could include concerts or gaming activities. The tender states that the campaign should use

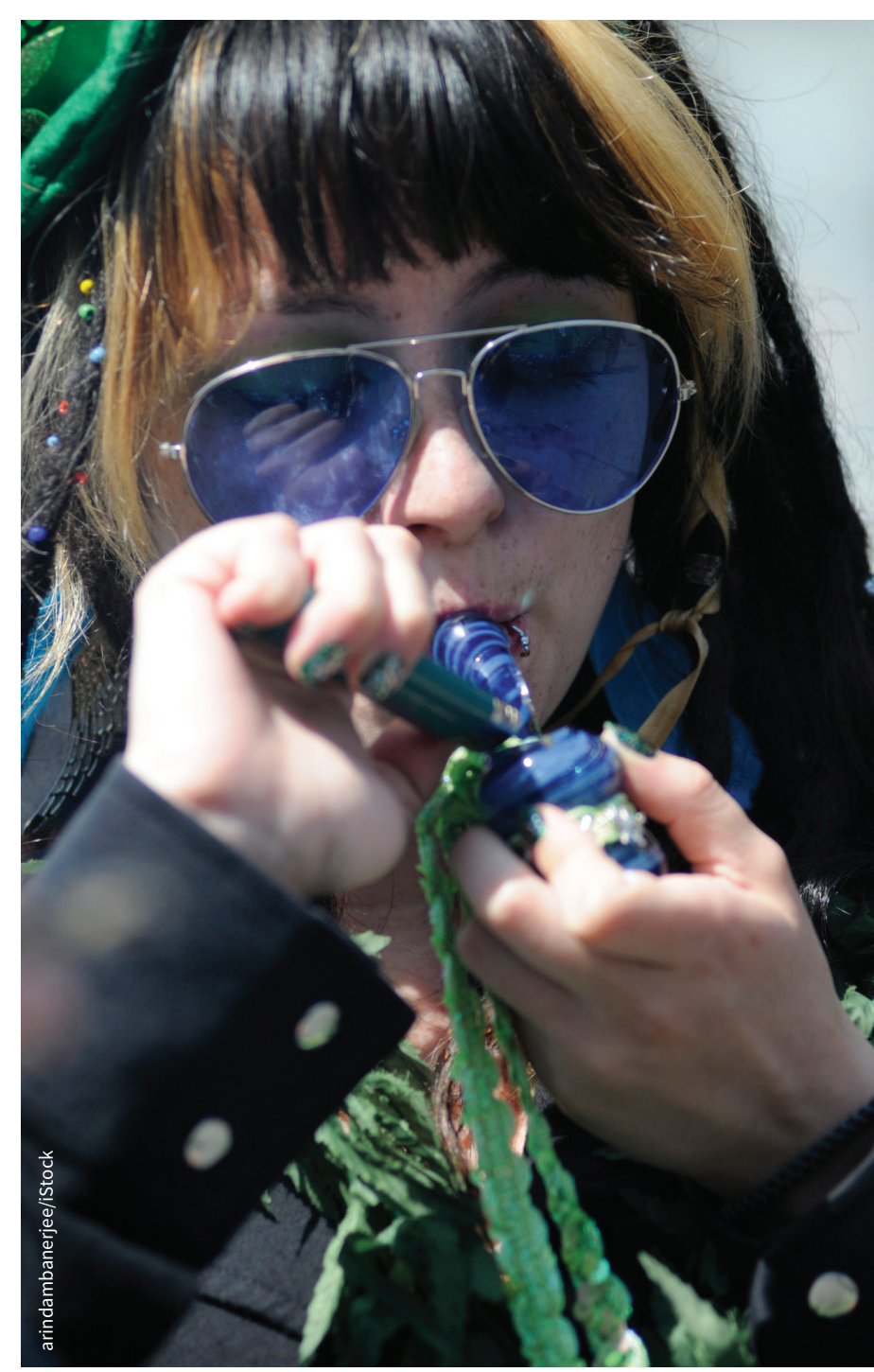

Health Canada plans to target Canadians age 13-24 in a campaign about the risks of using marijuana. communication channels popular among youth and engage popular bloggers or social media celebrities to encourage youth to attend events.

The tender outlines specific requirements for these events. In particular, the contractor for these events should have access to an existing social media following of at least 300000 people. Those managing the events are also asked to use "new and innovate method and technology that will appeal to young adults, in order to disseminate information on the health and safety risks of cannabis."

Bill C-45 states that the minimum legal age to purchase recreational marijuana would be 18 years old. Critics of the bill say it "fails to protect Canada's youth" and the Canadian Medical Association has recommended the minimum age to purchase cannabis should be 21 years old. The 2017 federal budget allocated \$9.6 million over five years (and \$1 million a year thereafter) for "marijuana public education programming and surveillance activities" as part of its stated commitment to keep cannabis "out of the hands of children."

Roger Collier, CMAJ 